\section{Banding together: an investigation of post-surgery support groups for laparoscopic adjustable gastric banding patients}

\author{
Melissa Opolski,1,2 Helen Winefield,1,2 \\ Cate Howell, 3 Jim Toouli, 3 Jane Collins, 3 \\ Lilian Kow ${ }^{3}$ \\ 1School of Psychology, University of \\ Adelaide; 2Discipline of Psychiatry, \\ School of Medicine, University of \\ Adelaide; ${ }^{3}$ Adelaide Bariatric Centre, \\ Flinders Private Hospital, Bedford Park, \\ Australia
}

\section{Abstract}

Though advocated as useful for patients, there is little in the literature regarding the use and effectiveness of bariatric support groups. This study investigated characteristics and experiences of bariatric patients who did and did not attend offered groups. Seventyeight postoperative laparoscopic adjustable gastric banding patients from a private bariatric clinic completed mailed self-report questionnaires. Almost 60\% reported having attended the clinic groups, with most wanting to meet other patients and obtain information rather than access psychological assistance. Participants reported generally positive experiences of attending. Nonattendance was often attributed to practical barriers. Satisfaction with support from others was not related to past or predicted future attendance, but higher psychological distress was related to and predictive of greater intention to attend future groups. Likely future attenders also held more positive beliefs about the groups than those who were unlikely to attend. Further research is required into potential positive and negative consequences of attendance, and characteristics of those who are likely to benefit or be harmed by attending. Interventions addressing stereotypes about support groups may help patients make informed decisions about whether to attend a bariatric support group.

\section{Introduction}

Bariatric surgeries are tools to help patients begin and sustain lifestyle changes that will support weight loss, ${ }^{1}$ but are not expected to override unhealthy lifestyle habits that might occur or recur after surgery, such as binging, grazing, emotional eating, and sedentary lifestyle. ${ }^{2-4}$ There is increasing recognition that many bariatric patients require access to psychosocial support to help them adapt to the challenging demands that often accompany bariatric surgery, including adopting new eating and exercise behaviors and developing strategies to cope with social and environmental problems, comorbid psychological disorders, and postsurgical emotional changes.5,6 In a study of individuals who had undergone weight loss surgery and felt that it had failed,? all noted that the surgery had neglected their mind (p.949) and that many had continued to use food for emotional regulation.

Like self-help and treatment groups, support groups are intended to offer a sense of community and safety, and generally involve periodic face-to-face meetings of a small number of people who have a common problem, disease, habit, condition, treatment, or stressor, but they differ by being led by a professional trained in the health or social sciences, who provides education and facilitates the sharing of experiences and support among participants. ${ }^{8,9}$ Bariatric support group meetings generally assist patients with the dietary and lifestyle changes that accompany their surgery, aiming to help individuals avoid returning to previous unhealthy habits, correct problematic eating patterns, increase compliance, improve psychosocial outcomes, provide a supportive environment to share successes and difficulties, identify challenges and high-risk situations and promote alternate behaviors and strategies to deal with these situations, and recognize any need for further assistance. ${ }^{10,11}$ Interestingly, they are assumed to be such an integral part of success that the American Society for Metabolic and Bariatric Surgery has made it mandatory for their Centers for Excellence to offer post-surgery support groups. ${ }^{11}$

\section{The evidence to date}

Despite emphasis on their provision, there is little accord in the limited literature regarding the use and efficacy of bariatric support groups. Support groups are inherently difficult to compare due to their variations in structure, duration, leadership, content, and activities, ${ }^{8}$ and methodological problems and variations make drawing conclusions even more challenging. A wide range of percentages of patients (26-68\%) of patients are reported as attending bariatric support groups. ${ }^{11-13}$ Further literature on bariatric support group attenders and non-attenders is limited. Hildebrandt reported that patients experiencing psychosocial, eating, or psychological problems were no more likely to have attended a support group, and there was no difference in the number of these problems reported by attenders versus non-attenders. 13 Further, bariatric patients' attitudes, beliefs, and practical reasons for
Correspondence: Helen Winefield, School of Psychology, University of Adelaide, South Australia 5005, Australia.

Tel.: +61.8.8313.3172 - Fax: +61.8.8313.3770.

E-mail: helen.winefield@adelaide.edu.au.

Key words: bariatric surgery, distress, support groups, attendance, beliefs.

Acknowledgements: the authors wish to thank each of the patients who gave their time and effort to participate in this study.

Contributions: the authors contributed equally.

Conflict of interests: M0 completed this research as part of a Master of Psychology (Health). She has provided clinical services to Adelaide Bariatric Centre since undertaking this study. $\mathrm{MO}, \mathrm{JC}$, and $\mathrm{CH}$ have all facilitated the investigated support groups.

Funding: this study was co-funded by the Discipline of Psychiatry, University of Adelaide and CM Consulting.

Received for publication: 29 March 2013

Revision received: 23 April 2013.

Accepted for publication: 24 April 2013.

This work is licensed under a Creative Commons Attribution NonCommercial 3.0 License (CC BYNC 3.0).

(O)Copyright M. Opolski et al., 2014

Licensee PAGEPress, Italy

Health Psychology Research 2014; 2:1464

doi:10.4081/hpr.2014.1464

support group attendance or nonattendance have shown no difference between group attenders and non-attenders in terms of practical barriers including travel distance and time required to get to the group, but family obligations were found to make attendance more difficult for non-attenders than attenders. ${ }^{11}$

Ussher et al. ${ }^{14}$ noted the importance of investigating support group use, including looking at attender and non-attender characteristics, identifying those who are likely to benefit from attending (and those who may not), and potential positive and negative consequences related to attendance or non-attendance. As there is likely to be a variety of reasons for support group attendance and nonattendance (potentially including beliefs, attitudes, expectations, experiences, and practical and logistical issues) investigation is needed into the reasons why individuals attend, do not attend, or do not reattend bariatric support groups. This study begins to act on this recommendation by exploring support group attendance by postoperative laparoscopic adjustable gastric banding (LAGB) patients, including links between demographic and psychosocial 
characteristics and past and predicted attendance, influence of beliefs about support groups and practical barriers to attendance, and reasons for attending, not attending, or not reattending.

\section{Materials and Methods}

\section{Participants}

The participants were 78 individuals aged 18-70 years $(\mathrm{M}=47.3 ; \mathrm{SD}=11.4)$ who had undergone LAGB between 3 November 2008 and 4 January 2010, an average of 309 days ( $\mathrm{SD}=117.1$; range=107-504) prior to participating in this study. The majority were female, married or in a de facto relationship, and reported little recent psychological distress. Table 1 shows further characteristics.

\section{Measures}

Each participant completed a questionnaire booklet containing questions about their demographic information (Table 1), surgery date, and items regarding the following issues.

\section{Experiences and opinions of the support groups}

Participants were asked whether they had ever attended the support group, and if so, how many sessions they had attended, and how soon after surgery they first attended. All were asked how likely it was that they would attend a future session (four-point scale: very likely very unlikely), and open-ended questions asked those who had previously attended (henceforth referred to as past attenders) or who said they were somewhat or very likely to attend a future group (likely future attenders) about why they had attended or would attend, while those who had not attended (past non- attenders) or who also said they were somewhat or very unlikely to attend (unlikely future attenders) were asked why they had not and would not attend. Past attenders were asked to describe anything they had found useful about attending, anything they had disliked or not found useful, and any concerns they had about their experience of attending. Past non-attenders who were unlikely future attenders were asked about reasons behind their nonattendance, while past attenders who were unlikely future attenders (non-reattenders) were asked why they would not reattend. Based on Orth $e t$ $a l ., 11$ all were asked their opinions (sevenpoint scales: strongly agree - strongly disagree) on 25 statements related to the support groups, including about their utility (e.g., clinic support groups would help me make healthy lifestyle choices) and difficulties that may influence attendance (e.g., clinic support groups are difficult to attend because I don't have enough time). Higher ratings indicated greater agreement with each statement.

\section{Psychological distress}

The Kessler-10 is a valid, reliable 10-item self-report measure of recent psychological distress, which asks respondents how often they experienced various symptoms over the past four weeks (five-point scale: none of the time - all of the time). 15

\section{Support from others}

The Multidimensional Support Scale is a reliable, valid, 16-item self-report measure of an individual's satisfaction, ${ }^{16}$ with the support they have received from their family and closest friends, peers (in this study, others who have had bariatric surgery), and experts (clinic medical staff who provided care for the participant) over the past four weeks. ${ }^{16}$ Participants indicated their opinion about the adequacy of various aspects of support (e.g. lis- tening) they had received from each source, as not enough (score of 1), too often (2), or it was just right (3). The subscale score for each source was averaged to allow comparisons.

\section{Procedure}

The groups under investigation have been available since late 2008 to all postoperative LAGB patients of a private bariatric clinic operating in two metropolitan South Australian locations. Frequency and times of the support groups differed by location from once a fortnight to once a month. The groups were promoted in pre-surgery patient literature, and most post-surgery patients were also personally invited to attend by a nurse. Patients were entitled to attend six group sessions without charge. The groups were facilitated by various practitioners including clinic nurses, a general practitioner, and a counselor, with assistance from postgraduate psychology and counseling students. Sessions ran for one hour with up to 15 patients attending, and varied in content but included the facilitators providing information and answering questions, participants sharing experiences, group discussion, and problem-solving of postsurgical medical and psychosocial issues.

Clinic nurses searched the clinic computerized patient database to identify all patients 18-85 years who had undergone a first LAGB between 3 November 2008 and 14 January $2010(\mathrm{~N}=426)$. Each was mailed a consent form, questionnaire booklet, and explanatory materials, with those wishing to participate asked to return their completed booklet and signed consent in the provided postage-paid envelope. After excluding seven potential respondents whose packs were returned to sender and two whose consent forms were not returned, 78 valid responses were received (19\% response rate).

Table 1. Participant demographic and psychosocial characteristics.

\begin{tabular}{lccc} 
Characteristic & $\%$ & Characteristic \\
$\begin{array}{l}\text { Gender (N=75) } \\
\text { Female }\end{array}$ & Lives with (N=74) & With others \\
Residential location (N=73) & 80.0 & Recent psychological distress (N=77) & None/low (K10 score 10-19) \\
$\quad$ Metropolitan area & & Mild (K10 score 20-24) & 94.6 \\
Large country center & 75.3 & Moderate (K10 score 25-29) \\
Small country town & 5.5 & Severe (K10 score 30-50) & 72.7 \\
Rural/remote location & 15.1 & Per annum household income (N=63), \$AUD \\
Relationship status (N=75) & 4.1 & $<50,000$ \\
Married or de facto relationship & & $50,000-89,999$ \\
Single & 77.3 & $\geq 90,000$ \\
Separated/divorced & 17.3 & Main employment status (N=69) \\
Highest level of education (N=73) & 5.3 & Full-time paid work \\
Some secondary school & & Part-time paid work \\
Secondary school/apprenticeship & 32.9 & Govt. benefit or unemployed \\
Certificate/diploma & 20.5 & Household/parenting work \\
Undergraduate degree & 13.7 & Retired \\
Postgraduate degree & 20.5 & \\
\hline
\end{tabular}




\section{Data analyses}

Analyses of categorical variables were conducted using chi-square tests $\left(\chi^{2}\right)$, continuous variables utilised Pearson's correlations $(r)$ or multiple regression, and those of categorical and continuous variables employed one-way between groups analyses of variance (ANOVA; $F$ ) with Tukey's HSD post-hoc tests. Effect sizes $\left(\eta^{2}\right)$ were interpreted as $0.01=$ small, $0.06=$ moderate, and $0.14=$ large, 17 and a 0.05 level of significance was utilized. Qualitative responses were analyzed using content analysis, a method allowing written, verbal, or visual data to be condensed into categories that share meaning and describe the material. ${ }^{18}$

\section{Results}

\section{Support group attendance}

More than half (58\%) of the participants reported having attended the clinic support group, with first attendance an average of 20.1 days post-surgery (range=6-84; $\mathrm{SD}=16.7$ ). Average attendance was 2.1 sessions (range $=1-8 ; \mathrm{SD}=2.0$ ): $63.6 \%$ had attended just one session, $20.4 \%$ had attended two or three, and $15.9 \%$ had attended more than three. Onethird of all participants (34\%), and a higher proportion of past group attenders (40\%) than those who had not attended previously (23\%), said they were somewhat or very likely to attend the support group in the future. No significant differences were found in the age groups, gender, marital status, household income, residential area, highest education level, and living with others or alone, of both past attenders and non-attenders, and predict- ed future attenders and non-attenders. Neither past attendance nor predicted future attendance were related to participants' satisfaction with the support they had received from family and friends, peers, or clinic medical staff, and no significant differences were found in the distress of past attenders and non-attenders. However, those who stated that they were likely to attend a future group reported significantly higher recent distress $(\mathrm{M}=20.3, \mathrm{SD}=10.3)$ than those who said they were unlikely to attend $(\mathrm{M}=16.1, \quad \mathrm{SD}=6.1), \quad F(1,73)=4.95$, $\mathrm{P}=0.029, \eta^{2}=0.06$. Participants with higher psychological distress were less satisfied with the support they received from family and friends $[r(67)=-0.44 ; \mathrm{P}<0.001]$ and bariatric clinic medical staff $[r(65)=-0.35 ; \mathrm{P}=0.004]$, though there was no association with satisfaction with support received from peers $[r(52)=$ $-0.22 ; \mathrm{P}=0.109]$.

\section{Beliefs about the groups}

Beliefs about the clinic support groups were generally positive, with highest average agreement ratings for statements that the clinic support group meetings would help me make healthy lifestyle choices $(\mathrm{M}=5.3, \mathrm{SD}=1.7)$, are useful to cope with post-surgery difficulties $(\mathrm{M}=4.8 \mathrm{SD}=1.9)$, and are necessary to lose weight after surgery $(\mathrm{M}=4.2, \mathrm{SD}=2.2)$. More neutral statements that the meetings are not needed by everyone $(\mathrm{M}=4.0, \mathrm{SD}=2.1)$, are helpful for some people, but not me ( $\mathrm{M}=4.0$, $\mathrm{SD}=2.3$ ), and would make no difference to how much weight I lose $(\mathrm{M}=3.7, \mathrm{SD}=2.3)$ received lesser support, while perceptions that they might make me feel worse $(\mathrm{M}=2.3, \mathrm{SD}=1.8)$ and are negative places $(\mathrm{M}=2.2, \mathrm{SD}=1.5)$ had the lowest average agreement. Significant dif- ferences were found between likely and unlikely future attenders' levels of agreement with opinions and beliefs about the support groups (Table 2). Likely future attenders had significantly higher levels of agreement than unlikely future attenders with the more positive statements about support groups (e.g. that they were useful, helpful for dealing with stress, and helpful for making healthy lifestyle choices), while unlikely future attenders agreed more with the neutral statements about the groups (e.g. that they were helpful for some but not for themselves, were not needed if an individual already had support, were not needed by everyone). No significant differences were found in past attenders' and non-attenders' agreement with these beliefs.

A hierarchical multiple regression examined the predictive ability of psychological distress and beliefs about the support groups on how likely participants believed they were to attend the clinic support group in the future. Demographic variables, surgery-related factors, and satisfaction with supports were not included as they were not significantly correlated with intention to attend, and only those beliefs that were significantly related to intention to attend were included (the clinical support groups are useful; are helpful for stress; are useful to learn ways to cope with postsurgery difficulties; are helpful for some people, but not me; more useful before than after surgery; would make me feel worse; are not needed by everyone; and are more useful before than after surgery). Recent psychological distress was entered at Step 1, explaining $8.6 \%$ of the variance $[F(1,59)=5.59, \mathrm{P}=0.02]$, and at Step 2, the entered beliefs about the support groups accounted for an additional

Table 2. One-way ANOVAs of opinions about the support groups held by participants who said they were likely and those who said they were unlikely to attend a future group session.

\begin{tabular}{|c|c|c|c|c|c|c|}
\hline The clinic support groups... & $\begin{array}{l}\text { M (SD) } \\
\text { Likely future attender } \\
(\max . \mathrm{n}=25)\end{array}$ & $\begin{array}{c}\text { Unlikely future } \\
\text { attender } \\
(\max . \mathrm{n}=44)\end{array}$ & F & df & $\mathbf{P}$ & $\eta^{2}$ \\
\hline ...would be useful before surgery & $5.4(1.9)$ & $5.3(1.6)$ & 0.11 & 1.66 & 0.742 & 0.002 \\
\hline ...would help me make healthy lifestyle choices & $5.7(1.7)$ & $4.3(1.9)$ & $9.23^{* *}$ & 1.63 & 0.003 & 0.13 \\
\hline ....are useful to learn ways to cope with post-surgery difficulties & $5.3(2.2)$ & $4.3(1.8)$ & $4.20^{*}$ & 1.63 & 0.045 & 0.06 \\
\hline$\ldots$ are useful & $5.4(2.1)$ & $4.1(2.0)$ & $6.40^{*}$ & 1.63 & 0.014 & 0.09 \\
\hline ....are necessary to lose weight after surgery & $4.7(2.2)$ & $3.9(2.2)$ & 2.24 & 1.65 & 0.141 & 0.03 \\
\hline ....are helpful to deal with stress & $5.1(1.6)$ & $3.5(1.9)$ & $12.29 * *$ & 1.64 & 0.001 & 0.16 \\
\hline ....are not needed by everyone after bariatric surgery & $3.3(2.0)$ & $4.4(2.0)$ & $4.19^{*}$ & 1.65 & 0.045 & 0.06 \\
\hline ....are helpful for some people, but not me & $3.0(1.9)$ & $4.6(2.3)$ & $7.83^{* *}$ & 1.62 & 0.007 & 0.11 \\
\hline ...would make no difference to how much weight I lose & $3.0(2.2)$ & $4.1(2.4)$ & 3.37 & 1.66 & 0.071 & 0.05 \\
\hline ...would be more useful before than after surgery & $2.7(1.6)$ & $4.1(1.9)$ & $9.25^{* *}$ & 1.64 & 0.003 & 0.13 \\
\hline ....aren't needed if you have enough support from other people & $2.8(1.9)$ & $4.0(2.1)$ & $5.05 *$ & 1.63 & 0.028 & 0.07 \\
\hline ....are only useful soon after surgery & $3.0(2.1)$ & $3.5(1.6)$ & 1.38 & 1.64 & 0.244 & 0.02 \\
\hline ...might make me feel worse & $1.6(1.4)$ & $2.7(1.9)$ & $5.58^{*}$ & 1.63 & 0.021 & 0.08 \\
\hline ....are negative places & $1.8(1.5)$ & $2.5(1.5)$ & 3.35 & 1.64 & 0.072 & 0.05 \\
\hline
\end{tabular}

M, mean; SD, standard deviation. Significant at ${ }^{*} \mathrm{P}<0.05,{ }^{*} \mathrm{P}<0.01$. 
$21.5 \%[F(7,52)=2.82, \mathrm{P}=0.04]$. Only psychological distress made a significant contribution to the model $(=-0.29, \mathrm{P}=0.03)$, with higher distress predictive of participants being more likely to believe they would attend the groups in the future. The total model accounted for $30.1 \%$ of the variance $\left[R^{2}=0.301\right.$; $F(8,52)=0.80, \mathrm{P}=0.01]$.

\section{Reasons for attending, not attending, or not reattending}

Content analysis was used to investigate participant reasons for attending, not attending, and not reattending the bariatric support groups (Table 3). Responses from past attenders and likely future attenders indicated that the most common reasons for attending were to meet, hear, and learn from other patients, and to receive guidance about general, physical/medical, psychological, and social issues from professionals. While the most common reasons for never attending were related to travel required to attend and not having time to attend due to other responsibilities, these issues were less commonly cited by those who were unlikely to reattend. Inconvenient days, times, and locations of the groups were the most commonlycited reason for not reattending.

\section{Experiences of attending the support group}

Content analyses of descriptions by past attenders about what they liked or found useful from attending the group and anything that they did not like or found concerning or problematic are presented in Table 4. Experiences of attending appeared generally positive, with a low percentage reporting problems or not finding anything useful or enjoyable about attending.

\section{Discussion and Conclusions}

Participant attitudes and beliefs about the groups were generally positive in this study. As previously reported by Orth et al.,11 no differences were found in past group attenders' and non-attenders' beliefs about bariatric support groups. However, likely future attenders held more positive beliefs about the groups than unlikely future attenders, including that they encourage healthy lifestyle choices and are useful to learn to cope with postoperative difficulties, and were less likely to agree that the groups weren't for everyone and that attending might make the individual feel worse. It may be valuable to address these specific attitudes and beliefs in any intervention encouraging support group attendance. If patients are less likely to attend the support groups because they hold unfounded negative beliefs or misperceptions about them, then attempts to change opinions, such as through providing information addressing typical misunderstandings about support groups, may allow more informed choices about attending. ${ }^{19}$

In this study, work, the days and/or times of meeting, not having enough time, living far away, and the group locations were rated as the most problematic practical barriers to attending or reattending the bariatric support groups. While Orth et al. ${ }^{11}$ reported more difficulty regarding family obligations for past bariatric support group non-attenders than attenders, here little difference was found in the difficulty posed by various practical barriers for those two groups.

According to Grande et al.,19 interventions are unlikely to affect either intention to attend a support group or actual attendance if individuals do not believe that the supposed benefits of attending are relevant to them, and any benefits may be irrelevant unless patients feel unsupported or are experiencing distress

Table 3. Content analyses of past attender/likely future attenders' reasons for attending, past non-attenders' reasons for not attending, and past attenders' reasons for not reattending.

\begin{tabular}{|c|c|c|c|c|c|}
\hline Reasons for attending ( $\mathrm{N}=33$ ) & $\%$ & Reasons for not attending ( $\mathrm{N}=33$ ) & $\%$ & Reasons for not reattending ( $\mathrm{N}=31$ ) & $\%$ \\
\hline Meet other patients (validate emotions, share experiences) & 87.9 & Distance (travel too far/expensive) & 42.4 & Inconvenient times, days, locations & 22.6 \\
\hline Professional guidance (ask questions, receive advice) & 54.5 & Other responsibilities (work, school, family) & 36.4 & Content (unanswered questions, repeated information) & 22.6 \\
\hline Guidance on physical issues & 24.2 & Format (prefer 1:1or alone, dislike groups) & 21.2 & No need to attend (doing well/have support) & 16.1 \\
\hline Guidance on psychosocial issues & 21.2 & Inconvenient times, locations & 18.2 & Forget sessions, unsure about times/locations & 9.7 \\
\hline Gain and sustain motivation & 18.2 & Unsure about times/locations & 15.2 & Groups too far to travel & 9.7 \\
\hline \multirow[t]{4}{*}{ Learn about later postoperative issues } & 12.1 & No need to attend (have enough support) & 15.2 & Other responsibilities & 9.7 \\
\hline & & Do not wish to attend & 9.1 & Have attended available sessions & 6.5 \\
\hline & & & & $\begin{array}{l}\text { Participantffacilitator factors (varying needs, disliked } \\
\text { facilitator) }\end{array}$ & 6.5 \\
\hline & & & & Do not like group setting & 3.2 \\
\hline
\end{tabular}

Table 4. Content analysis of what past group attenders liked or found useful $(\mathrm{N}=33)$ and disliked or found concerning or problematic $(\mathrm{N}=30)$ about attending the support group.

\begin{tabular}{|c|c|c|c|}
\hline Positives & $\%$ & Negatives & $\%$ \\
\hline $\begin{array}{l}\text { Format (inc. discussions, being able to ask questions, } \\
\text { all having chance to speak) }\end{array}$ & 12.1 & $\begin{array}{l}\text { Issues with participants/facilitators (inc. group too diverse, female } \\
\text { dominated, individuals dominating, negative attitudes, } \\
\text { too many participants, questions not answered) }\end{array}$ & 36.6 \\
\hline $\begin{array}{l}\text { Meeting/learning from others in similar situation, } \\
\text { sharing stories, learning that others were facing similar issues }\end{array}$ & 63.6 & None & 26.7 \\
\hline $\begin{array}{l}\text { Professional advice/answers (inc. helpful, well-presented } \\
\text { information on eating, body changes, behavior change) }\end{array}$ & 27.3 & $\begin{array}{l}\text { Issues with content/format (inc. focus on early postop. issues, } \\
\text { repeated or not enough information, lack of 1:1 consultation) }\end{array}$ & 19.9 \\
\hline Bond between participants, supporting each other & 18.2 & Inconvenient times, location changes & \\
\hline Facilitator support, patience, manner, reassurance & 12.1 & Issues with setting (inc. felt uncomfortable in public area) & 6.7 \\
\hline \multirow[t]{2}{*}{ Nothing } & 9.1 & Negative atmosphere, not useful, did not enjoy attending & 9.9 \\
\hline & & Unsure of times/locations, forget about groups & 3.3 \\
\hline
\end{tabular}


related to their surgery. In this study, satisfaction with support from others was not related to past or predicted future attendance, but higher distress was related to greater intention to attend in the future and more positive perceived norms regarding attendance, indicating that more distressed patients felt that their significant others were more positive about their attending the support groups. It is common for psychological support to be stigmatized and viewed as only appropriate for those who are in significant distress. ${ }^{20}$ Unsurprisingly, lower satisfaction with family and friends and clinic medical staff support was also associated with greater recent distress. Participant reasons for attending were informative about what they hoped to gain from attending the bariatric support groups. The highest proportion wished to meet others who had undergone the surgery, to discuss and compare experiences, problems, and strategies with them, and to access guidance, advice, and information from professionals on physical and psychosocial issues. Although further research is required, education about support groups and normalizing attendance appear important to ensure that support groups, and especially those that do not predominantly focus on emotional support, are not perceived as appropriate only for those who are experiencing high levels of distress. ${ }^{20}$ However, it is important to remember that some people may not benefit from accessing support, and support groups may not be the most appropriate means of support for every individual. While the majority of past group attenders in this study reported having had a positive experience of the groups, there were nonetheless also some more negative ones. There is little literature regarding the characteristics of those for whom attending a group is likely to be beneficial, those who are likely to experience little or no effect from attending, and those for whom attending may be harmful, as well as how these benefits and harms may manifest. Prospective studies into these issues would provide valuable information. Kinzl $e t$ $a l .5$ note that patients with good psychosocial support and coping skills for postoperative adjustment are generally difficult to motivate to access post-surgery psychological support , and may not actually benefit from (or could even be harmed by) accessing psychological support anyway. For example, Helgeson et al. ${ }^{21}$ found that although peer discussion groups were helpful for women with breast cancer who lacked adequate support, the physical functioning of women in the groups who began with high levels of support actually deteriorated. The major limitations of this study were its cross-sectional design, which meant that the causal direction between relationships could not be inferred, ${ }^{19}$ and potential problems regarding generalizability. The low response rate in the study suggests a possibility of self-selection bias, and incomplete records also made it impossible to draw comparisons between study respondents and nonrespondents. The sample was also recruited from patients of a private surgery clinic, who may have a different demographic profile to those attending a publicly-funded clinic. Significant further research is needed to clarify the evidence from this preliminary research; however the present results provide a useful foundation for such efforts.

\section{References}

1. McMahon MM, Sarr MG, Clark MM, et al. Clinical management after bariatric surgery: value of a multidisciplinary approach. Mayo Clin Proc 2006;81:S34-45.

2. Colles SL, Dixon JB. Night eating syndrome: impact on bariatric surgery. Obes Surg 2006;16:811-20.

3. Elkins G, Whitfield P, Marcus J, et al. Noncompliance with behavioural recommendations following bariatric surgery. Obes Surg 2005;15:546-51.

4. Saunders R. Grazing: a high-risk behaviour. Obes Surg 2004;14:98-102.

5. Kinzl JF, Trefalt E, Fiala M. Psychotherapeutic treatment of morbidly obese patients after gastric banding. Obes Surg 2002;12:292-4.

6. Saunders R. Post-surgery group therapy for gastric bypass patients. Obes Surg 2004;14:1128-31.

7. Ogden J, Avenell S, Ellis G. Negotiating control: patients' experiences of unsuccessful weight-loss surgery. Psychol Health 2011;26:949-64.

8. Gottlieb BH, Wachala ED. Cancer support groups: a critical review of empirical studies. Psychooncology 2007;16:379-400.
9. Schopler JH, Galinsky MJ. Support groups as open systems: a model for practice and research. Health Soc Work 1993;18:195207.

10. Marcus JD, Elkins GR. Development of a model for a structured support group for patients following bariatric surgery. Obes Surg 2004;14:103-6.

11. Orth WS, Madan AK, Taddeucci RJ, et al. Support group meeting attendance is associated with better weight loss. Obes Surg 2008;18:391-4.

12. Elakkary E, Elhorr A, Aziz F, et al. Do support groups play a role in weight loss after laparoscopic adjustable gastric banding? Obes Surg 2006;16:331-4.

13. Hildebrandt SE. Effects of participation in bariatric support group after Roux-en-Y gastric bypass. Obes Surg 1998;8:535-42.

14. Ussher J, Kirsten L, Butow P, Sandoval M. What do cancer support groups provide which other supportive relationships do not? The experience of peer support groups for people with cancer. Soc Sci Med 2006;62:2565-76.

15. Kessler RC, Mroczek DK. Final version of our non-specific psychological distress scale. Thesis dissertation. Ann Arbor, MI: University of Michigan; 1994.

16. Winefield HR, Coventry BJ, Lewis M, Harvey EJ. Attitudes of patients with breast cancer toward support groups. J Psychosoc Oncol 2003;21:39-54.

17. Cohen J. Statistical power analysis for the behavioural sciences. Hillsdale, NJ: Erlbaum; 1988.

18. Sandelowski M. Qualitative analysis: what is it and how to begin? Res Nurs Health 1995; 18:371-5.

19. Grande GE, Myers LB, Sutton SR. How do patients who participate in cancer support groups differ from those who do not? Psychooncology 2006;15:321-34.

20. Ussher J, Kirsten L, Butow P, Sandoval M. A qualitative analysis of reasons for leaving, or not attending, a cancer support group. Soc Work Health Care 2008;47:1429.

21. Helgeson VS, Cohen S, Schulz R, Yasko J. Group support interventions for women with breast cancer: who benefits from what? Health Psychol 2000;19:107-14. 